\title{
Activation of Wnt/ $\beta$-catenin signaling to increase BMI1 by Licl attenuates the toxicity of cisplatin in the HEI-OC1 auditory cells
}

\section{Yingpeng $\mathrm{Xu}$}

Children's Hospital of Nanjing Medical University

\section{Chen Sun}

Children's Hospital of Nanjing Medical University

Chen Lu

Children's Hospital of Nanjing Medical University

Yaqing Liu

Children's Hospital of Nanjing Medical University

Ling Lu

Nanjing Drum Tower Hospital

Qi Li ( $\nabla$ liqi71520@hotmail.com )

Children's Hospital of Nanjing Medical University

\section{Research Article}

Keywords:

Posted Date: March 6th, 2021

DOI: https://doi.org/10.21203/rs.3.rs-267578/v1

License: (1) This work is licensed under a Creative Commons Attribution 4.0 International License. Read Full License 


\title{
Activation of Wnt/ק-catenin signaling to increase BMI1 by Licl
}

\section{attenuates the toxicity of cisplatin in the HEI-OC1 auditory cells}

\author{
Yingpeng $\mathrm{Xu}^{1 *}$, Chen Sun ${ }^{1 *}$, Chen $\mathrm{Lu}^{1}$, Yaqing $\operatorname{Liu}^{1}$, Ling $\mathrm{Lu}^{2}$, Qi $\mathrm{Li}^{1,3^{\Delta}}$ \\ 1 Department of ENT, Children's Hospital of Nanjing Medical University, Nanjing, Jiangsu, PR China \\ 2 Department of ENT, Affiliated Drum Tower Hospital of Nanjing University Medical School,Nanjing, \\ Jiangsu, PR China \\ 3 Medical School of Nanjing University, Nanjing, Jiangsu, PR China \\ * Contributed equally \\ $\Delta$ Correspondence to: Prof Qi Li, Children's Hospital of Nanjing Medical University, Nanjing, Jiangsu, \\ 210008, PR China. Email: liqi71520@hotmail.com
}

\begin{abstract}
Cisplatin is a very effective anti-tumor drug; nonetheless, it can induce cochlear hair cell apoptosis and ototoxicity in large doses. WNT/ $\beta$-catenin signaling is also closely related to aging, embryonic development, and apoptosis. We establish a cisplatin-induced HEI-OC1 auditory cells model. WNT/ $\beta$-catenin was activated by GSK3 inhibitor Licl to detect the expression level of each component of the WNT pathway and BMI1. The expression of BMI1 in the hair cell line model of HEI-OC1 cells induced by cisplatin was significantly reduced, and cell apoptosis was significantly reduced by increasing the expression level of cell line BMI through activating $\mathrm{WNT} / \beta$-catenin signaling. Activation of $\mathrm{WNT} / \beta$-catenin signaling to increase BMI1 expression can reduce the apoptosis of cochlear hair cells induced by cisplatin. BMI1 also has a protective effect on the ototoxicity of cisplatin.
\end{abstract}

Keywords: Wnt/ $\beta$-catenin; BMI1; Cisplatin; Ototoxicity; HEI-OC1 cells

\section{Introduction}

Since cisplatin was first used for treating patients with a malignant tumor in 1971, platinum has increasingly become an essential chemical drug in the treatment of 
tumors due to its wide anti-tumor spectrum and remarkable clinical effect. However, large doses of cisplatin can lead to bilateral sensorineural deafness, mainly damaging the cochlea. Cochlear hair cells are one of the three main targets of cisplatin damage to the cochlea, which can be caused by direct or indirect means such as the direct effect of cisplatin accumulation in the inner ear, the influence of nucleic acid metabolism, oxidative stress injury, apoptosis ${ }^{[1]}$, and autophagy ${ }^{[2]}$. Some studies have shown that GSK-3 inhibitors can inhibit cisplatin-induced apoptosis by increasing the expression of $\beta$-catenin in the nucleus so as to reduce p53 activity, and reduce the expression of target genes such as P21, PUMA, PARP, p53, etc., thus suggesting that the GSK-3/ $\beta$-catenin pathway may have a central role in cisplatin mediated HEI-OC1 cell cytotoxicity [3]. Wnt pathway has a certain role in the ototoxicity of cisplatin; nonetheless, its specific pathogenic mechanism is still not perfect.

The $\mathrm{Wnt} / \beta$-catenin pathway is very conservative in biological evolution, and its members have a high degree of homology from lower animals to higher mammals, which regulates the stability of transcription cofactor $\beta$-catenin and depends on its expression. ${ }^{[4]}$ It has been found that, when the Wnt signal exists, Wnt protein binds to the Frizzled receptor $(\mathrm{Fz})$ on the cell membrane, triggering the phosphorylation of the LDL-receptor-related protein 5/6 (LRP5/6) and the formation of the FZ-LRP5/6 complex. The phosphorylated LRP5/6 is affinitive with Axin protein, and the Glycogen synthase kinase 3 (GSK3) and the Casein kinase 1(CK1), which binds to Axin phosphorylates LRP5/6 to further promote LRP5/6 binding to Axin. Through DEP and PDZ domains, Dishevelle (Dvl) is combined with Fz. Dvl and Axin have the same DIX 
domain, and the formed complex can promote the formation of the wnt-FZ-LRP5/6 complex, thus preventing the phosphorylation of $\beta$-catenin ${ }^{[5]}$. In contrast, Wnt binds to Fz to activate CK1 on the inner side of the cell membrane, after which the activated CK1 phosphorylate Dv1 and release GSK3 binding protein (GBP), where GBP can recognize and bind GSK3, inhibit GSK3 phosphokinase activity, and prevent stepped phosphorylation of $\beta$-catenin. Thus, when Wnt signaling is present, the formation of the Wnt receptor complex promotes the disintegration of the degradation complex, which leads to the accumulation of $\beta$-catenin. When $\beta$-catenin accumulates in the cytoplasm, it is transported to the nucleus by a variety of enzymes. $\beta$-catenin in the nucleus activates the transcription complex by binding to a low-affinity $\mathrm{N}$-terminal coincidence site instead of Groucho/TLE binding to Tcf/Lef. ${ }^{[6]}$

BMI1 has a vital role in stimulating cell proliferation, inhibiting proteins, and cell embryo development. BMI1 inhibits Ink4a/Arf gene sites by co-acting with C-Myc protein, and has a dominant-negative regulatory effect on the transcription of p16Ink4a and p19Arf, and regulates cell-reproduction and apoptosis through the ARF-MDM2-p53 pathway [7]. It was found that the down-regulation of BMI1 significantly inhibited the proliferation of Corti organ cells during the embryonic development of Corti organ in the inner ear. It has also been shown that Bmil regulates the proliferation of cochlear support cells through the classic WNT/ $\beta$-catenin signaling ${ }^{[8]}$, thus having a role in the development of the inner ear and auditory-related diseases. As this protective effect has not yet been studied in the ototoxicity of drugs, in the 
present study, we established the HEI-OC1 cell ototoxicity model by cisplatin to study the role of BMI1 and WNT/ $\beta$-catenin signaling in the ototoxicity of cisplatin.

\section{Results}

\section{Cisplatin induces apoptosis in HEI-OC1 hair cells}

A

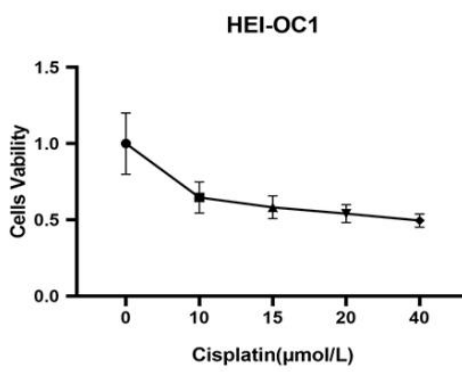

C

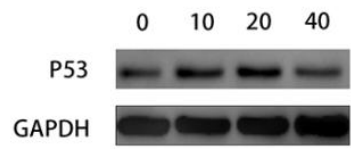

merge

B

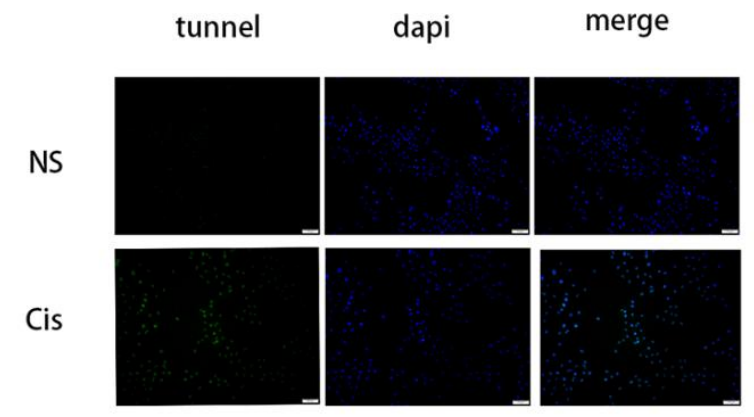

Fig.1 Cisplatin-induced apoptosis of HEI-OC1 hair cells. (A) CCK-8 cell proliferation assay: HEI-OC1 hair cells were treated with 0, 10, 15, 20, and $40 \mu \mathrm{mol} / \mathrm{L}$ cisplatin for $24 \mathrm{~h}$. As the concentration gradient rises, cell activity is lower $(N=6, P<0.05$ vs. NS). (B) Immunofluorescence: hair cells treated with $20 \mu \mathrm{mol} / \mathrm{L}$ cisplatin for $24 \mathrm{~h}$. The apoptosis of the cisplatin group was more obvious. (C) Western Blot: HEI-OC 1 cells were treated with 0, 10, 15, 20, $40 \mu \mathrm{mol} / \mathrm{L}$ cisplatin for $24 \mathrm{~h}$. With the increase of the cisplatin concentration gradient, P53 overall showed an upward trend.

In order to verify the effect of cisplatin on HEI-OC1 hair cells, we treated HEI-OC1 hair cells with cisplatin solution of $0,10,15,20$, and $40 \mu \mathrm{mol} / \mathrm{L}$, respectively 
for $24 \mathrm{~h}$. The cell activity was detected by CCK-8 cell assay, which showed that the cell activity decreased with the increase of cisplatin concentration (Fig. 1A). In order to understand the apoptosis of cells, we found that the apoptosis of cells in the cisplatin group significantly increased by Tunel staining between the control group and the cisplatin group (Fig. 1B). The effect of cisplatin on the apoptosis of heI-OC1 hair cells was also reflected in the protein level. The expression level of the classical apoptotic factor P53 increases with the increase of cisplatin concentration. $(\mathrm{P}<0.05)($ Fig. 1C). Although the expression of P53 in the $40 \mu \mathrm{mol} / \mathrm{L}$ cisplatin treatment group was slightly lower than before, the toxicity of cisplatin had a greater effect on HEI-OC1 hair cells, and the damaged cells were less able to adhere to the walls, while the apoptotic cells were more likely to be washed and dropped. Consequently, high doses of cisplatin could not be selected to treat the cells. In general, the ototoxicity of cisplatin can induce higher apoptosis with the increasing concentration of cisplatin. For further experiments, we selected $20 \mathrm{~mol} / \mathrm{L}$ as the optimal concentration of cisplatin. 


\section{Cisplatin-induced deactivate of Wnt/ß-catenin signaling in HEI-OC1 auditory}

cells

A

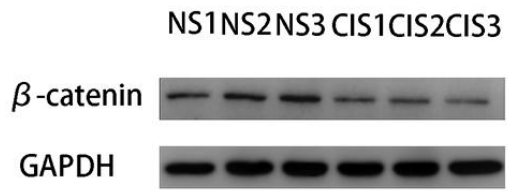

B

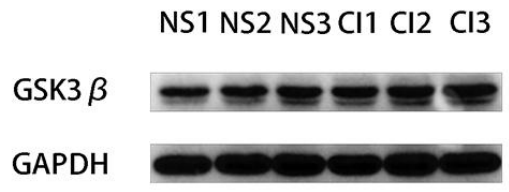

GSK3 $\beta$

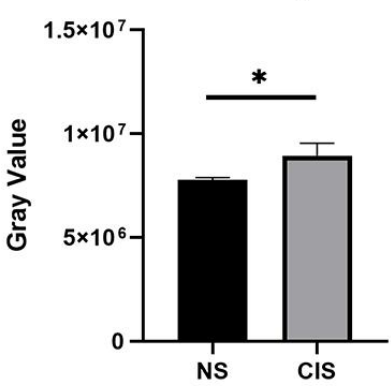

Fig. 2 Cisplatin-induced deactivation of Wnt/B-catenin signaling in HEI-OC1 cells. (A) Western Blot: the expression of $\beta$-catenin was inhibited after HEI-OCl cells were treated with $20 \mu \mathrm{mol} / \mathrm{L}$ cisplatin for $24 \mathrm{~h}$. Grayscale analysis showed that the data were significant $(N=3$, $P=0.0148<0.05)$. (B) Western Blot: the expression of GSK3 protein was increased in HEI-OC1 cells treated with $20 \mu \mathrm{mol} / \mathrm{L}$ cisplatin for $24 \mathrm{~h}$. Grayscale analysis showed that the data were significant $(N=3, P=0.0285<0.05)$.

In order to explore the relationship between the ototoxicity of cisplatin and $\mathrm{Wnt} / \beta$-catenin signaling, we detected the changes in protein levels of each component of Wnt/ $\beta$-catenin signaling between cisplatin group and normal group by Western Blot. As a key factor in $\mathrm{Wnt} / \beta$-catenin signaling, the expression level of total $\beta$-catenin in cells decreased with the increase of cisplatin concentration $(\mathrm{P}<0.05)($ Fig. 2A). $\beta$-catenin can activate the transcription complex through Tcf/Lef, while the reduction of $\beta$-catenin undoubtedly limits the influence of $\mathrm{Wnt} / \beta$-catenin signaling on 
downstream pathways. A recent study has shown that cisplatin can promote the apoptosis of HEI-OC1 cells by activating GSK3 ${ }^{[9]}$, which was also demonstrated in our experiments. In HEI-OC1 cells treated with $20 \mu \mathrm{mol} / \mathrm{L}$ cisplatin, GSK3 expression level was increased $(\mathrm{P}<0.05)($ Fig. $2 \mathrm{~B})$; the activation of GSK3 promoted the step-phosphorylation of $\beta$-catenin and degradation, which may be one of the reasons for the decreased expression level of $\beta$-catenin caused by cisplatin. In conclusion, cisplatin can induce the deactivation of Wnt/ $\beta$-catenin signaling in HEI-OC1 cells.

Cisplatin activates ARF-MDM2-p53 signaling by reducing BMI1 expression, leading to apoptosis

A

NS1 NS2NS3 Cl1 Cl2 Cl3
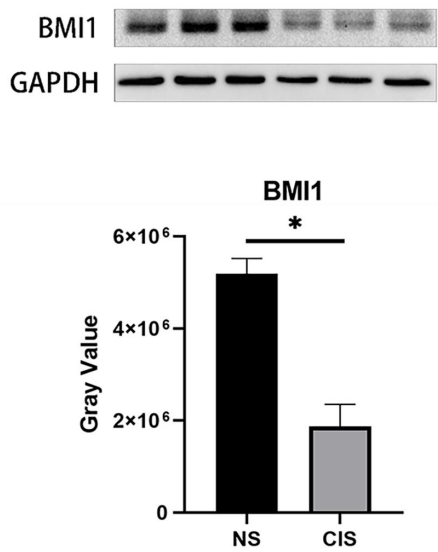

B

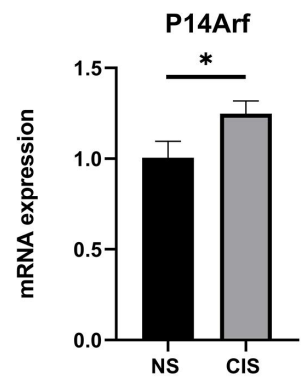

C
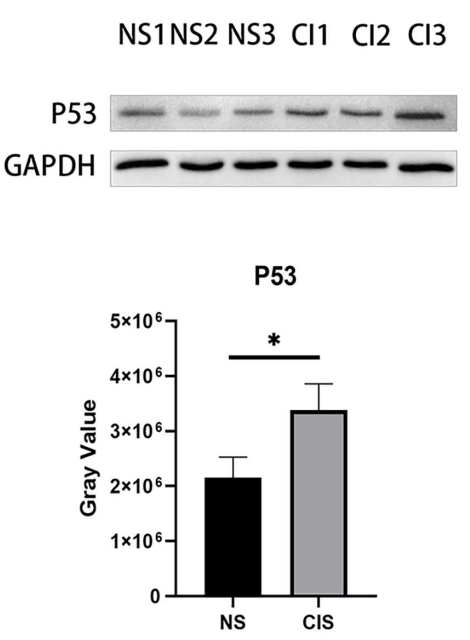

D

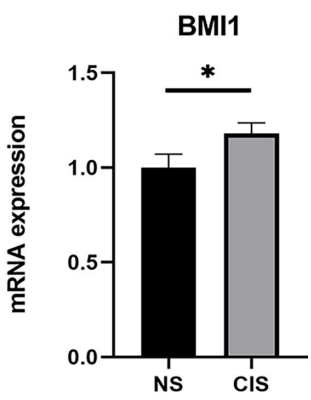


Fig.3 Cisplatin activates the ARF-MDM2-p53 signaling by reducing the expression of BMI1, leading to apoptosis. (A) Western Blot: the expression of BMI1 protein was inhibited after HEI-OC1 cells were treated with $20 \mu \mathrm{mol} / \mathrm{L}$ cisplatin for $24 \mathrm{~h}$. The grayscale analysis showed that the data was significant $(N=3, P=0.0006<0.05)$. (B) QPCR: HEI-OCl cells were treated with $20 \mu \mathrm{mol} / \mathrm{L}$ cisplatin for $24 \mathrm{~h}$, and the mRNA expression of P14ARF and P53 were increased. $(N=3, P=0.0216,0.0086<0.05)$. (C) Western Blot: when HEI-OCl cells were treated with $20 \mu \mathrm{mol} / \mathrm{L}$ cisplatin for $24 \mathrm{~h}$, the protein level of P53 increased. The grayscale analysis showed that the data were significant $(N=3, P=0.0006<0.05)$. (D) QPCR: HEI-OCI cells were treated with $20 \mu \mathrm{mol} / \mathrm{L}$ cisplatin for $24 \mathrm{~h}$, and the $\mathrm{mRNA}$ expression of BMII was increased. $(N=3, P=0.0252<0.05)$

Studies have reported that BMI1, which is involved in the development of age-related hearing loss, can regulate cell apoptosis through the ARF-MDM2-p53 signaling ${ }^{[10]}$. In order to verify whether BMI1 has a similar role in cisplatin-induced hair cell injury, we detected the expression of BMI1 related proteins and genes in the HEI-OC1 cell ototoxicity model by cisplatin. Western Blot analysis revealed that the expression of BMI1 significantly decreased $(\mathrm{P}<0.05)($ Fig. 3A). Our results showed that combined with C-Myc, BMI1 can inhibit Ink4a/Arf gene and has a negative regulatory effect on Ink4a and Arf transcription ${ }^{[9]}$. The mRNA levels of P14ARF and P53 were significantly increased (Fig. 3B), and the increased level of P53 protein indicated the increased level of apoptosis (Fig. 3C). These results indicated that BMI1 was involved in cell apoptosis through the ARF-MDM2-p53 signaling. However, the expression of the mRNA of the BMI1 did not reduce, and was even slightly elevated (Fig. 3D), which suggested that the decrease of BMI1 was not caused by the decrease of transcription level, but probably by protein consumption. This, in turn, may be caused by the reduction of apoptosis caused by the combination of BMI1 and C-Myc. However, other possibilities cannot be ruled out and need to be verified by further studies. 


\section{Licl can attenuate cisplatin-induced apoptosis}

A

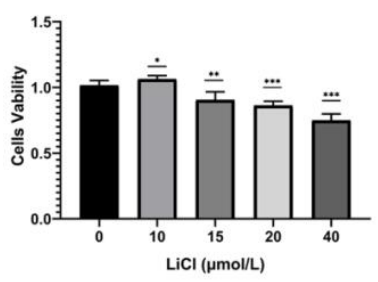

B

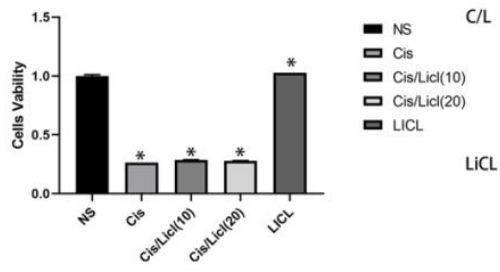

C

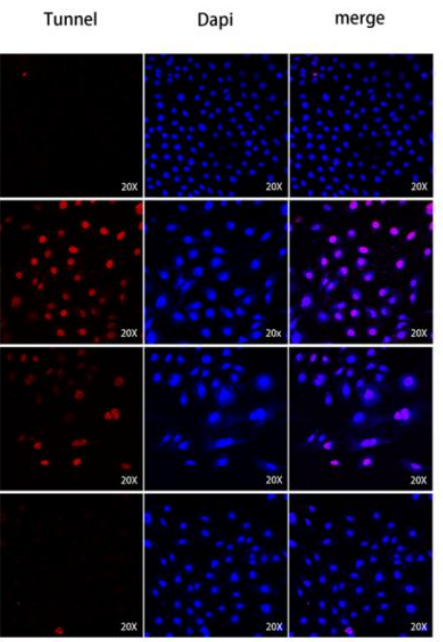

Fig.4 Licl can attenuate cisplatin-induced apoptosis. (A) CCK-8: HEI-OC1 cells were treated with $0,10,15,20$, and $40 \mathrm{mmol} / \mathrm{L}$ Licl for $24 \mathrm{~h}$, respectively. The cell activity increased at $10 \mathrm{mmol} / \mathrm{L}$ and then decreased with the increase of concentration (N=6,P<0.05vs. NS). (B) HEI-OCl cells were treated with air culture, air culture, $10 \mathrm{mmol} / \mathrm{L} \mathrm{Licl} \mathrm{for} 24 \mathrm{~h}$, and then with air culture, $20 \mu \mathrm{mol} / \mathrm{L}$ cisplatin, $20 \mu \mathrm{mol} / \mathrm{L}$ cisplatin, $10 \mathrm{mmol} / \mathrm{L} \mathrm{Licl} \mathrm{for} 24 \mathrm{~h}$. It can be seen from CCK-8 that Licl group suffered a lower loss of cell activity in cisplatin's toxicity compared to the cisplatin group. (C) Tunnel staining: Tunnel staining showed that HEI-OCI cells were treated with air culture, air culture, $10 \mathrm{mmol} / \mathrm{L}$ Licl for $24 \mathrm{~h}$, and then treated with air culture, $20 \mu \mathrm{mol} / \mathrm{L}$ cisplatin, $20 \mu \mathrm{mol} / \mathrm{L}$ cisplatin, and 10mmol/L Licl for $24 \mathrm{~h}$, respectively, so as to determine the degree of apoptosis through Tunnel staining. It can be seen that the apoptosis of HEI-OCl cells treated with $10 \mathrm{mmol} / \mathrm{L} \mathrm{Licl}$ was significantly reduced in the cisplatin toxicity.

Licl is an inhibitor of GSK3, which can reduce the degradation of $\beta$-catenin by inhibiting GSK3 and activating the Wnt/ $\beta$-catenin signaling [11], which can protect HEI-OC1 cells from cisplatin ototoxicity. Licl itself has low toxicity. In this study, we treated HEI-OC1 cells with $0,10,15,20$, and $40 \mathrm{mmol} / \mathrm{L}$ Licl. Interestingly, when we treated HEI-OC1 cells at a low concentration of $10 \mathrm{mmol} / \mathrm{L}$, lithium chloride would not damage cells but improve cell activity (Fig. 4A). In order to verify whether the protective effect of lithium chloride could be continued in the HEI-OC1 cell ototoxicity 
model by cisplatin, it could be seen from CCK-8 that the cell activity of the Licl group increased compared with the other groups (Fig. 4B). Further Tunnel staining results also suggested that the apoptosis of HEI-OC1 cells treated with $10 \mathrm{mmol} / \mathrm{L} \mathrm{Licl} \mathrm{was}$ significantly reduced in the cisplatin toxicity (Fig.4C). As a GSK3 inhibitor, this protective effect of Licl was obviously closely related to the Wnt/ $\beta$-catenin signaling.

\section{Activation of Wnt/ß-catenin signaling by Licl can increase the expression of BMI1}

and inhibit the ARF-MDM2-p53 signaling

A

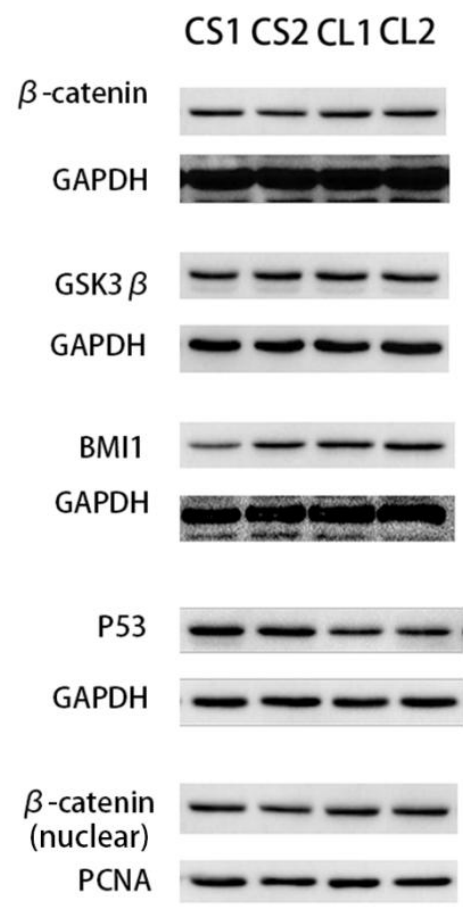

B

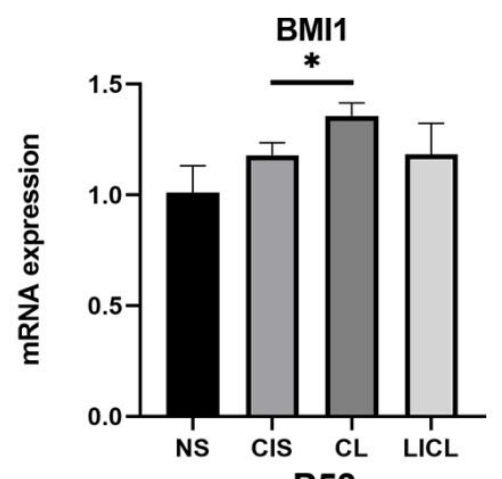

C

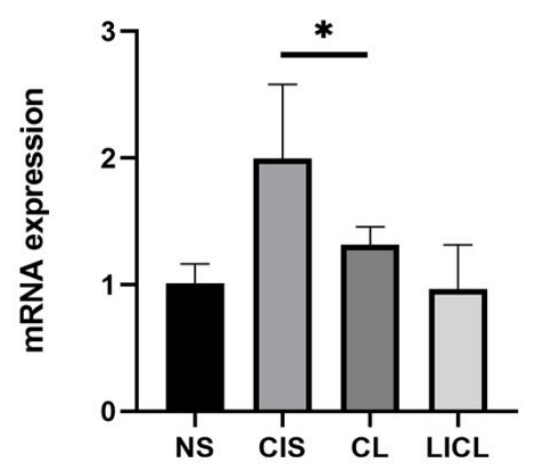

Fig.5 Activation of Wnt/B-catenin signaling by Licl can increase the expression of BMII and inhibit the ARF-MDM2-p53 signaling. (A) Western Blot: the changes in the expression levels of various proteins in cells after HEI-OCl were respectively treated with air culture and $10 \mathrm{mmol} / \mathrm{L} \mathrm{Licl} \mathrm{for} 24 \mathrm{~h}$ and then $20 \mu \mathrm{mol} / \mathrm{L}$ cisplatin for $24 \mathrm{~h}$. (B) QPCR: expression of the BMII mRNA after HEI-OCl was treated with empty culture and 10mmol/L Licl for $24 \mathrm{~h}$ and then $20 \mu \mathrm{mol} / \mathrm{L}$ cisplatin for $24 \mathrm{~h}$, respectively. $(N=3, P=0.0193<0.5)$. (C) $q P C R$ : expression 
of BMII mRNA after HEI-OC1 was treated with empty culture and 10mmol/L Licl for $24 \mathrm{~h}$ and $20 \mu \mathrm{mol} / \mathrm{L}$ cisplatin for $24 \mathrm{~h}$, respectively. $(N=3, P=0.0388<0.5)$.

Licl is a GSK3 $\beta$ inhibitor that can activate Wnt signaling. By constructing the HEI-OC1 cisplatin ototoxicity model with Licl intervention, we observed that the expression level of GSK3 was lower in the Licl group than in the cisplatin group. This indicated that the inhibition of GSK3 by Licl was effective; the ladder phosphorylation of $\beta$-catenin was inhibited, the expression of $\beta$-catenin was increased (Fig.5A), and Licl successfully activated the $\mathrm{Wnt} / \beta$-catenin signaling. Accumulated $\beta$-catenin was transported into the cell nucleus and the concentration of $\beta$-catenin in the nucleus increased (Fig. 5A). Nuclear $\beta$-catenin may bind to TCF/LEF and activate downstream transcription factors. Coincidentally, the expression of BMI1 mRNA in the Licl group compared with the cisplatin group was further increased (Fig. 5B), which showed that Licl could indeed increase the transcription of BMI1 and improve the expression of BMI1 by activating the Wnt/ $\beta$-catenin signaling. It is well known that BMI1 can bind C-Myc and inhibit the ARF-MDM2-p53 signaling, resulting in a decrease in the gene expression level of P53 (Fig. 5C) and a synchronous decrease in the protein level of P53 (Fig. 5A). Therefore, activation of Wnt/ $\beta$-catenin signaling by Licl could increase the expression of BMI1 and inhibit the ARF-MDM2-p53 signaling.

\section{Discussion}

Our results revealed that Licl could reduce the damage to hair cells caused by cisplatin. The purpose of this study was to investigate the specific mechanism of Wnt signaling activation on the protective effect of cochlear hair cells in cisplatin toxicity. 
The role of Wnt signaling in cell proliferation and differentiation is more widely known. Wnt signaling, which is a marker of embryonic development with different roles at different stages of embryonic development, is involved in the structure-specific generation of the ear, formation of vestibular structure, and development of cochlea in the hearing system ${ }^{[12]}$. In mammals, the damage to cochlear hair cells is usually irreversible, and the lost auditory hair cells cannot be spontaneously replaced. However, the Wnt signaling can stimulate Atoh1 to activate the differentiation ability to support cells, where differentiated outer hair cells can participate in both morphology and function ${ }^{[13]}$. We observed that in the HEI-OC1 hair cells treated with cisplatin, the activated WNT signaling could protect hair cells and reduce hair cells' apoptosis. This protective effect on hair cells is rarely reported, and the mechanism is unclear. Therefore, we assumed that Licl activates the Wnt signaling, increases the transcription of BMI1, inhibits the ARF-MDM2-p53 signaling, and reduces apoptosis.

BMI1 is commonly found in tumor cells and is closely related to cell proliferation and regeneration. Studies have found that increased expression of BMI1 can reduce hearing loss ${ }^{[10]}$. Since mammalian hair cells generally do not replace themselves when they are lost, these hair cells are not derived from proliferation and regeneration after loss, and they are likely to benefit from the protective effect of BMI1. Our experiments proved that BMI1 was involved in the process of cochlear hair cells apoptosis caused by cisplatin, and the expression level of BMI1 protein was significantly decreased in the HEI-OC1 hair cells injury caused by cisplatin. Interestingly, the expression of BMI1 mRNA was negatively increased, which may be a regulation of feedback. It also 
suggested that the reduction of BMI1 is wasting, and BMI1 consumes itself in some ways to reduce the ototoxicity of cisplatin to HEI-OC1 hair cells. It is highly likely that BMI1 inhibits the ARF-MDM2-p53 signaling by binding with C-Myc protein. Our results revealed that the expression of BMI1 did have a certain degree of correlation with the ARF-MDM2-p53 signaling pathway by increasing and decreasing the expression of BMI1; however, further studies are needed to clarify these results.

At the same time, we observed the inhibition of $\mathrm{Wnt} / \beta$-catenin signaling caused by cisplatin ototoxicity; however, it remains unclear whether the Wnt pathway's inhibition is affected by the increase of GSK3 is caused by cisplatin or by the decrease of BMI1. A previous study has shown that BMI1 knockout leads to inhibition of Wnt/ $\beta$-catenin signaling ${ }^{[14]}$ and high expression of BMI1 by inhibiting the Wnt/ $\beta$-catenin signaling inhibitor DKK1 activation of Wnt ${ }^{[15]}$. Accordingly, we activated $\mathrm{Wnt} / \beta$-catenin signaling through $\mathrm{LiCl}$ to increase protein and gene expression level of BMI1, and reduce cell apoptosis, thus proving that the regulation of BMI1 and Wnt/ $\beta$-catenin signaling is not unidirectional but bidirectional.

Previous studies have not elucidated how did Licl protect HeI-OC1 cells. It is well known that the ototoxicity of cisplatin is generated through various functions. It has been shown that Licl can improve the body's ROS level ${ }^{[16]}$, which is more likely to lead to cisplatin's cell damage through oxidative stress. Therefore, we did not believe that Licl's protective effect was achieved by reducing oxidative stress. Also, there was no direct chemical reaction between Licl and cisplatin, which could not reduce the 
content of cisplatin and reduce the direct damaging effect of cisplatin. Therefore, Licl should participate in reducing cell apoptosis.

Our results revealed that Licl could activate the Wnt signaling and increase the transcription of BMI1. Moreover, our results revealed that highly expressed BMI1 protein reduces the expression of P53 mRNA through the negative feedback regulation of P14ARF, thus suggesting that BMI1 can indeed reduce the apoptosis of cells through the ARF-MDM2-p53 signaling. This may be a novel site to protect cochlear hair cells from the ototoxic of cisplatin. By inhibiting the expression of GSK3, LiCl activates the Wnt signaling leading to the accumulation of $\beta$-catenin in the nucleus, which binds to TCF/LEF and improves the expression of BMI1 at the transcriptional level. At the same time, studies have shown that the protective effect of Bmil may be related to the enhancement of the antioxidant system and the accumulation of mitochondrial superoxide dismutase, which is achieved by directly targeting SOD 1 and SOD 2 regulated by FoxO1 ${ }^{[17]}$. BMI1 can also maintain the survival of hair cells by controlling the REDOX balance and reactive oxygen species ${ }^{[18]}$. Therefore, the mechanism of BMI1's protective effect on hair cells may not be unique, but it is expected to protect cochlear hair cells from the ototoxic drug by increasing the expression of BMI1.

In summary, our results revealed that the high expression of $\mathrm{Wnt} / \beta$-catenin signaling in HEI-OC1 hair cells reduced the apoptosis induced by cisplatin. Next, we confirmed the protective effect of BMI1 on the ototoxic of cisplatin in HEI-OC1 cells. 
Finally, we demonstrated that $\mathrm{Wnt} / \beta$-catenin signaling in HEI-OC1 cells regulates BMI1 expression, thus reducing the ARF-MDM2-p53 signaling mediated apoptosis. Our study suggests that BMI1 is necessary for the protection of HEI-OC1 cells from cisplatin-induced apoptosis, and BMI1 may be a novel target for the prevention of cisplatin-induced apoptosis in HEI-OC1 hair cells.

\section{Materials and Methods}

\section{Ethics}

Our study was approved in writing by the Institutional Animal Care and Use Committee of NJMU (Approval number IACUC-2006008).

\section{Cell model}

This study was reviewed and approved by the Institutional Review Board of the Hospital. HEI-OC1 hair cells (Southeast University, Chai Lab) were cultured in DMEM (Gibco, 11965092) supplemented with 10\% fetal bovine serum (Gibco,10099, Austrilia) at $37{ }^{\circ} \mathrm{C}$ and $5 \% \mathrm{CO} 2$. DMEM solution of $0,10,15,20$, and $40 \mu \mathrm{mol} / \mathrm{L}$ cisplatin (Qilu Pharma, $20 \mathrm{mg}$ ) was used for $24 \mathrm{~h}$ to establish the ototoxicity model of cisplatin. DMEM solution of $0,10,15,20$ and $40 \mathrm{mmol} / \mathrm{L}$ lithium chloride (Sigma,L4408,100 g) was used for $24 \mathrm{~h}$, and the optimal concentration of lithium chloride was selected. Finally, the HEI-OC1 cell model was treated with $10 \mathrm{mmol} / \mathrm{L}$ lithium chloride DMEM solution for $24 \mathrm{~h}$. Then the HEI-OC1 cell was cultured with 
$20 \mu \mathrm{mol} / \mathrm{L}$ cisplatin for $24 \mathrm{~h}$ so as to establish the model of the protective effect of lithium chloride on the ototoxicity of cisplatin.

\section{CCK-8}

Cells were cultured on a 96-well plate, and a cell model was established. Briefly, $10 \mu \mathrm{L}$ of CCK-8 detection reagent (KGA317) was added to each well and incubated at $37^{\circ} \mathrm{C}$ for $1 \mathrm{~h}$. Fluorescence detector (Promega GloMax96) was used for detection at the wavelength of $450 \mathrm{~nm}$, cell activity $=($ experimental group absorbance - control group absorbance)/ experimental group absorbance.

\section{Protein extraction}

After the cell model was established, the cells were rinsed with PBS three times, an appropriate amount of RIPA lysate (Biyun Sky, P0013B) was added, cells were scraped and broken with ultrasound, protein concentration was measured by BCA method (Biyun Sky, P0010), and SDS-PAGE protein loading buffer (Biyun Sky, P0015L) was added, and then boiled and stored at $-80{ }^{\circ} \mathrm{C}$. Fresh cell tissue was extracted with nuclear protein and cytoplasmic protein extraction kit (Shanghai Yishan, ES0005), the protein concentration was measured by the BCA method (Biyuntian, P0010). SDS-PAGE protein loading buffer (Biyuntian, P0015L) was added, and boiled and stored at $-80^{\circ} \mathrm{C}$.

\section{Western Blot}


$10 \%$ and $12 \%$ SDS-PAGE gels were prepared by using SDS-PAGE gel preparation kit (Biyun Sky, P0012A), and 40 to $50 \mu \mathrm{g}$ target protein was added to each well, and the first hole to join $10 \mu 1$ marker protein (Thermo, 26616). Electrophoresis was performed with a Bio-rad gel electrophoresis apparatus at $100 \mathrm{~V}$ for $2 \mathrm{~h}$, after which the protein was transferred onto PVDF membrane, and sealed with TBST solution of 5\% skimmed milk powder for $1 \mathrm{~h}$, and incubated overnight at $4 \mathrm{C}$ with the appropriate dilution of the following antibody: anti- $\beta$-catenin (1:1000, Abcam, 9562S), anti-GSK3 (1:1000, Abcam,9315s), anti-p53(1:1000, Abcam,32532s), Anti-BMI1 (1:1000, Abcam,5856s), anti-GAPDH (1:1000, ABsin, ABS137959). Next, secondary antibodies were added (1:1000, HRP-goat anti-Rabbit IgG, H+L, Beyond, A0208) to work in normal temperature for $1 \mathrm{~h}$, were washed with TBST for 3 times, development solution was added (Tiangen, PA112-02), after which imaging with Bio-rad ChemiDoc XRS+ was performed.

\section{Quantitative real-time PCR}

The total RNA of fresh HEI-OC1 cells was extracted and treated with Trizol and then reverse-transcribed with HiScript II Q RT SuperMix for qPCR (Vazyme, R222-01). The unstable RNA was reversed transcribed into relatively stable cDNA, which was stored at $-20^{\circ} \mathrm{C}$. Through AceQ qPCR SYBR Green Master Mix (High ROX Premixed) $10 \mu 1$ kit configuration system, including $1 \mu \mathrm{l}$ cDNA, $0.4 \mu \mathrm{l}$ primers $3.2 \mu \mathrm{DEPC}$ water and $5 \mu \mathrm{l} \mathrm{SYBR}$ Green Real-time PCR Master Mix, using Roche Light Cycler 96 PCR testing, and $2^{\wedge}(-\Delta \Delta \mathrm{CT})$ method were used to detect the expression of RNA. Primers 
for the qPCR (listed in Table 1) used for amplification were designed using Primer Premier 5.0 software (Premier Biosoft International, USA).

Table 1. The nucleotide sequences of the primers that were used in the real-time PCR analysis with SYBR Green.

\begin{tabular}{|c|c|c|}
\hline Gene & Sequence (5'-3') & \\
\hline \multirow{4}{*}{ BMI1 } & Forward: & \multirow[t]{2}{*}{5 , } \\
\hline & ATCCCCACTTAATGTGTGTCCT & \\
\hline & Reverse: & 5 ' \\
\hline & CTTGCTGGTCTCCAAGTAACG & \\
\hline \multirow{4}{*}{ P53 } & Forward: & \multirow[t]{2}{*}{$5^{\prime}$} \\
\hline & CTCTCCCCCGCAAAAGAAAAA & \\
\hline & Reverse: & \multirow[t]{2}{*}{$5^{\prime}$} \\
\hline & CGGAACATCTCGAAGCGTTTA & \\
\hline \multirow{4}{*}{ P14ARF } & Forward: & \multirow[t]{2}{*}{5 ' } \\
\hline & CGCAGGTTCTTGGTCACTGT & \\
\hline & Reverse: & $5^{\prime}$ \\
\hline & TGTTCACGAAAGCCAGAGCG & \\
\hline \multirow{4}{*}{$\beta$-actin } & Forward: & 5 ' \\
\hline & GGCTGTATTCCCCTCCATCG & \multirow{3}{*}{$5^{\prime}$} \\
\hline & Reverse: & \\
\hline & CCAGTTGGTAACAATGCCATGT & \\
\hline
\end{tabular}

\section{Immunofluorescence staining detection:}

In order to determine the condition of cell apoptosis, cell culture was carried out on a confocal culture dish to establish a cell model. Cells were incubated with the one-step TUNEL cell apoptosis detection kit (BEYOND, C1090), washed in PBS three times, and the nucleus was stained with DAPI staining solution (BEYOND, P0131). The 
labeled cells were detected with a laser scanning confocal microscope (Zeiss, $\operatorname{LSM710).~}$

\section{Statistical analysis}

Experimental data were expressed as mean \pm standard deviation $(\mathrm{x} \pm \mathrm{s})$, and a t-test was used for the comparison of the two samples. For comparison of multiple samples with a single factor, one-way ANOVA was used, and $\mathrm{P}<0.05$ was considered statistically significant.

\section{Acknowledgments}

This study was supported by Nanjing medical science and technology development fund key project (number: ZKX19041)

\section{Author Contributions}

X.Y.P, S.C and L.Q conceived and designed the experiments. X.Y.P, L.C and S.C performed the experiments. S.C, L.Q, and L.L provided technical advice for the experimental procedures. X.Y.P and S.C analyzed data and drafted the paper. X.Y.P, S. C, L.Y.Q. and L.Q participated in the revision of the manuscript. S.C and L.Q provided the conceptual framework for the study, directed and coordinated the project. All authors approved the final version of the manuscript.

\section{Competing interests}

The authors declare no competing interests.

\section{References}

1. Santos N A G D , Ferreira R S , Santos A C D . Overview of cisplatin-induced neurotoxicity and ototoxicity, and the protective agents - ScienceDirect[J]. Food and Chemical Toxicology, 136. 
2. Chen $\mathrm{Y}$, Li L , Ni W , et al. Bmi1 regulates auditory hair cell survival by maintaining redox balance[J]. Cell Death \& Disease, 2015, 6(1):e1605.

3. Yong-Il, Kim, Seung, et al. Activation of beta-catenin by inhibitors of glycogen synthase kinase-3 ameliorates cisplatin-induced cytotoxicity and pro-inflammatory cytokine expression in HEI-OC1 cells[J]. Toxicology: An International Journal Concerned with the Effects of Chemicals on Living Systems, 2014, 320:74-82.

4. Kappel E C V , Maurice M M. Molecular regulation and pharmacological targeting of the $\beta$ - catenin destruction complex[J]. British Journal of Pharmacology, 2017, 174(24).

5. Katoh M,Katoh M.Molecular genetics and targeted therapy of WNT-related human diseases (Review)[ J]. Int J Mol Med,2017,40(3): 587-606.

6. Kappel E C,Maurice M M.Molecular regulation and pharmacological targeting of the beta-catenin destruction complex[J]. Br J Pharmacol,2017,174(24): 4575-4588.

7. Tang D,He Y,Li W,et al.Wnt/beta-catenin interacts with the FGF pathway to promote proliferation and regenerative cell proliferation in the zebrafish lateral line neuromast[J]. Exp Mol Med,2019,51(5): 1-16.

8. Bassioun M , Aurélie Dos Santos, Avci H X, et al. Bmi1 Loss in the Organ of Corti Results in p16ink4a Upregulation and Reduced Cell Proliferation of Otic Progenitors In Vitro[J]. PLOS ONE, 2016.

9. Xia M Y,Zhao X Y,Huang Q L,et al.Activation of Wnt/beta-catenin signaling by Licl attenuates d-galactose-induced neurodegeneration in the auditory cortex of a rat model of aging[J]. FEBS Open Bio,2017,7(6): 759-776.

10. Park Hee-Je,Kim Hyung-Jin,Bae Gi-Sang et al.Selective GSK-3beta inhibitors attenuate the cisplatin-induced cytotoxicity of auditory cells.[J].Hear Res,2009,257: 53-62.

11. Lu X , Sun S ,Qi J , et al.Bmi1Regulates the Proliferation of Cochlear Supporting Cells Via the Canonical Wnt Signaling Pathway.[J]. Molecular Neurobiology,2016,54(2): 1-14.

12. Zak M,Klis S F,Grolman W.The Wnt and Notch signalling pathways in the developing cochlea: Formation of hair cells and induction of regenerative potential[J]. Int J Dev Neurosci,2015,47(Pt B):247-258...

13. Yamashita T,Zheng F,Finkelstein D,et al.High-resolution transcriptional dissection of in vivo Atoh1-mediated hair cell conversion in mature cochleae identifies Isl1as a co-reprogramming factor[J]. PLoS Genet,2018,14(7): e1007552.

14. Erika Ló pez-Arribillaga, Veró nica Rodilla, Pellegrinet L, et al. Bmi1 regulates murine intestinal stem cell proliferation and self-renewal downstream of Notch[J]. Development, 2015, 142(1):41-50.

15. Cho Joon-Ho,Dimri Manjari,Dimri Goberdhan P,A positive feedback loop regulates the expression of polycomb group protein BMI1via WNT signaling pathway.[J].J Biol Chem,2013,288: 3406-18.

16. Lee Yunkyoung,Kim Sang-Min,Jung Eun-Hye et al.Licl promotes lipid accumulation through increased reactive oxygen species generation.[J].Biochim Biophys Acta Mol Cell Biol Lipids,2020,1865: 158552.

17. Zhu Guoxia,Wu Yongxiang,Qiu Yang et al.Hsp70/Bmi1-Fox01-SOD Signaling Pathway Contributes to the Protective Effect of Sound Conditioning against Acute Acoustic Trauma in a Rat Model.[J].Neural Plast,2020,2020: 8823785. 
18. Chen $\mathrm{Y}, \mathrm{Li} \mathrm{L}, \mathrm{Ni} \mathrm{W}$ et al.Bmi1regulates auditory hair cell survival by maintaining redox balance.[J].Cell Death Dis,2015,6: e1605. 


\section{Figures}

\section{Cisplatin induces apoptosis in HEI-OC1 hair cells}

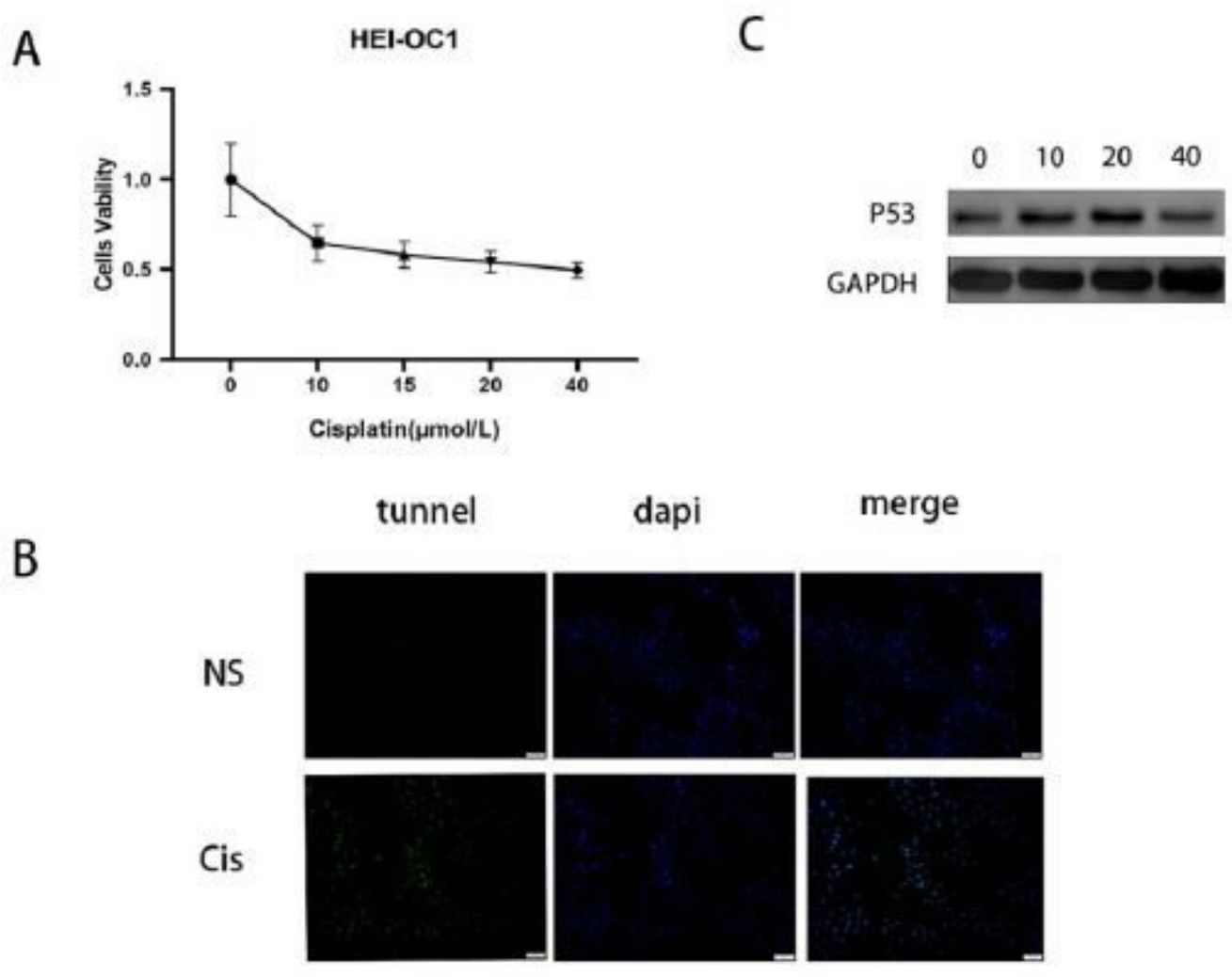

\section{Figure 1}

Cisplatin-induced apoptosis of HEI-OC1 hair cells. (A) CCK-8 cell proliferation assay: HEI-OC1 hair cells were treated with $0,10,15,20$, and $40 \mu \mathrm{mol} / \mathrm{L}$ cisplatin for $24 \mathrm{~h}$. As the concentration gradient rises, cell activity is lower ( $N=6, P<0.05$ vs. NS). (B) Immunofluorescence: hair cells treated with $20 \mu \mathrm{mol} / \mathrm{L}$ cisplatin for $24 \mathrm{~h}$. The apoptosis of the cisplatin group was more obvious. (C) Western Blot: HEl-OC 1 cells were treated with $0,10,15,20,40 \mu \mathrm{mol} / \mathrm{L}$ cisplatin for $24 \mathrm{~h}$. With the increase of the cisplatin concentration gradient, P53 overall showed an upward trend. 
A

\section{NS1NS2NS3 CIS1CIS2CIS3}

$\beta$-catenin

GAPDH

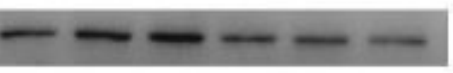

B

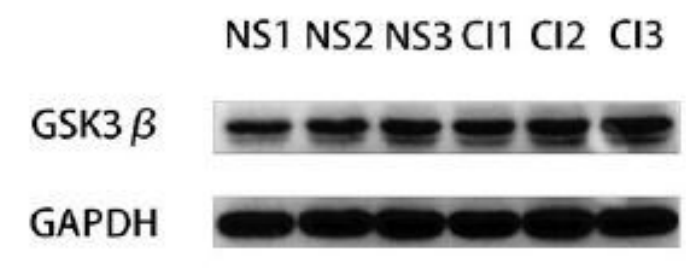

NS1 NS2 NS3 Cl1 Cl2 Cl3

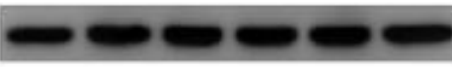

$\beta$-catenin

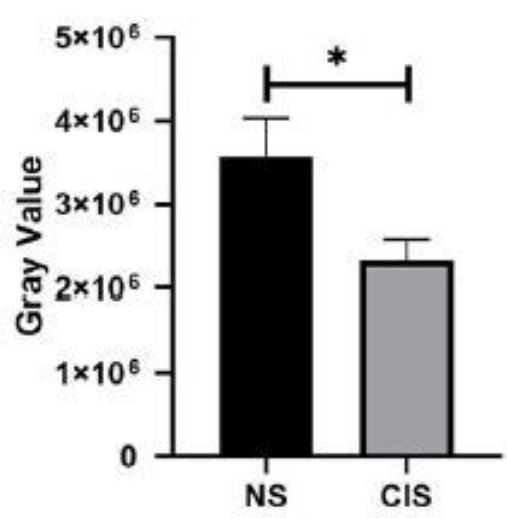

GSK3ß

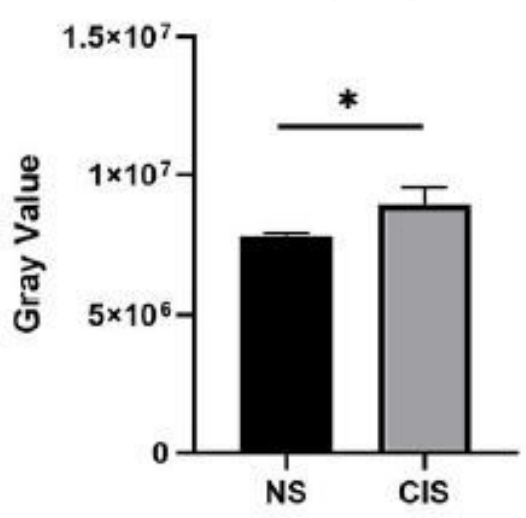

Figure 2

Cisplatin-induced deactivation of Wnt/ $\beta$-catenin signaling in HEI-OC1 cells. (A) Western Blot: the expression of $\beta$-catenin was inhibited after HEl-OC1 cells were treated with $20 \mu \mathrm{mol} / \mathrm{L}$ cisplatin for $24 \mathrm{~h}$. Grayscale analysis showed that the data were significant $(N=3, P=0.0148<0.05)$. (B) Western Blot: the expression of GSK3 protein was increased in HEI-OC1 cells treated with $20 \mu \mathrm{mol} / \mathrm{L}$ cisplatin for $24 \mathrm{~h}$. Grayscale analysis showed that the data were significant $(N=3, P=0.0285<0.05)$. 
A

NS1 NS2NS3 $\mathrm{Cl} 1 \mathrm{Cl}_{2} \mathrm{Cl} 3$

BMI1

GAPDH
C

NS1NS2 NS3 $\mathrm{Cl} 1 \mathrm{Cl} 2 \mathrm{Cl} 3$

P53

GAPDH

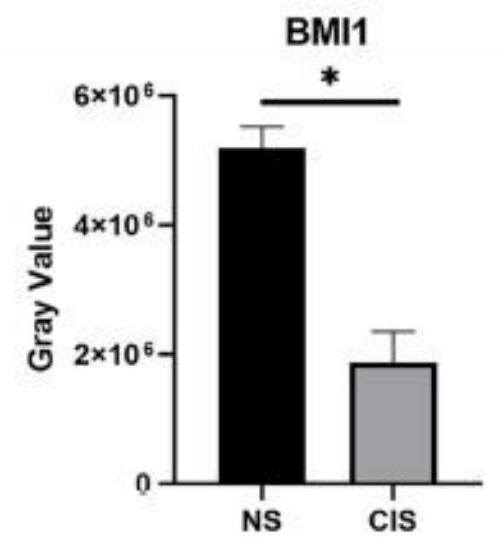

B

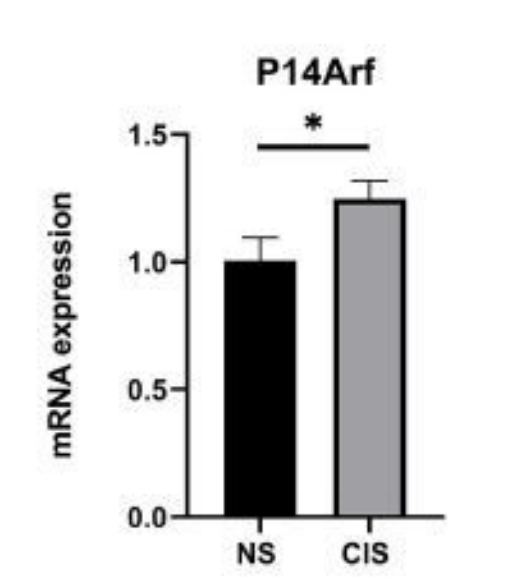

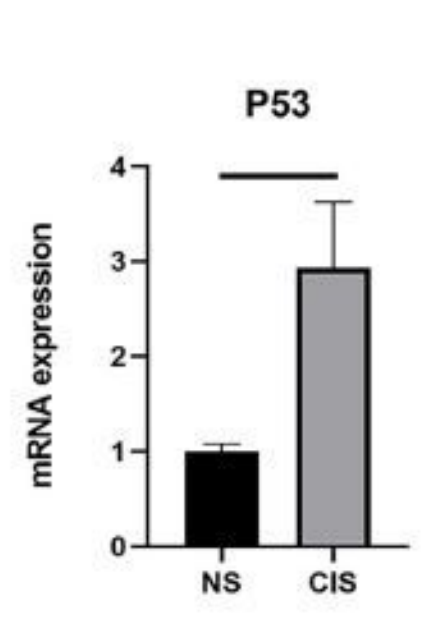

P53

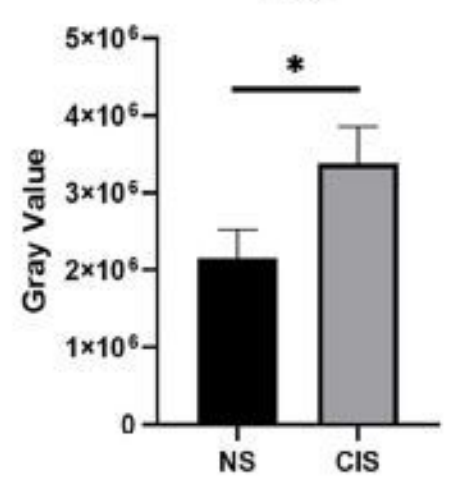

D

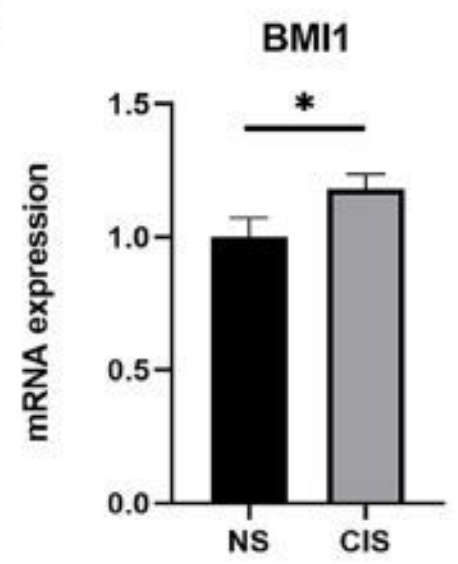

\section{Figure 3}

Cisplatin activates the ARF-MDM2-p53 signaling by reducing the expression of BMI1, leading to apoptosis. (A) Western Blot: the expression of BMI1 protein was inhibited after HEl-OC1 cells were treated with $20 \mu \mathrm{mol} / \mathrm{L}$ cisplatin for $24 \mathrm{~h}$. The grayscale analysis showed that the data was significant $(\mathrm{N}=3$, $\mathrm{P}=0.0006<0.05$ ). (B) QPCR: HEl-OC1 cells were treated with $20 \mu \mathrm{mol} / \mathrm{L}$ cisplatin for $24 \mathrm{~h}$, and the mRNA expression of P14ARF and P53 were increased. $(N=3, P=0.0216,0.0086<0.05)$. (C) Western Blot: when $\mathrm{HEI}-\mathrm{OC} 1$ cells were treated with $20 \mu \mathrm{mol} / \mathrm{L}$ cisplatin for $24 \mathrm{~h}$, the protein level of P53 increased. The grayscale analysis showed that the data were significant $(N=3, P=0.0006<0.05)$. (D) QPCR: HEI-OC1 cells were treated with $20 \mu \mathrm{mol} / \mathrm{L}$ cisplatin for $24 \mathrm{~h}$, and the mRNA expression of BMl1 was increased. $(\mathrm{N}=3$, $\mathrm{P}=0.0252<0.05$ ) 
A

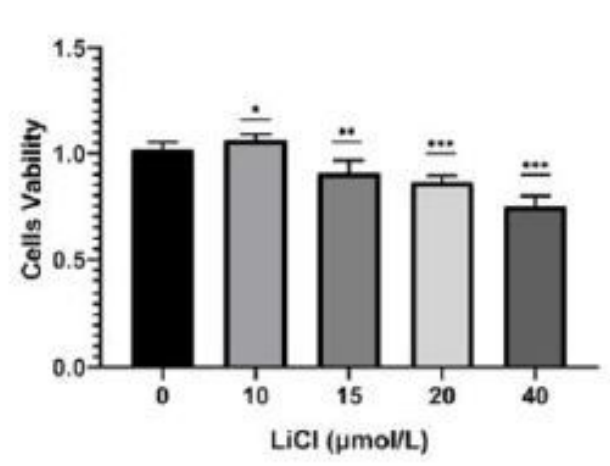

C

B

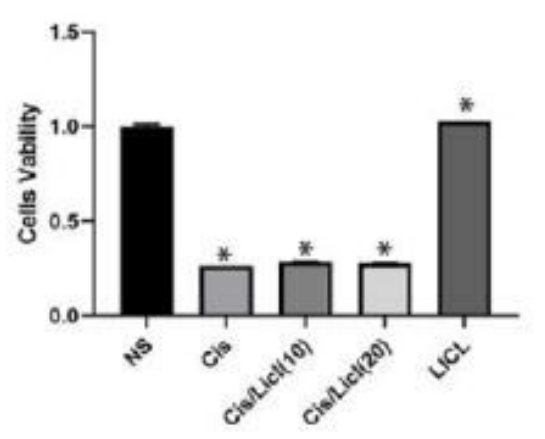
NS

CIS

$c$
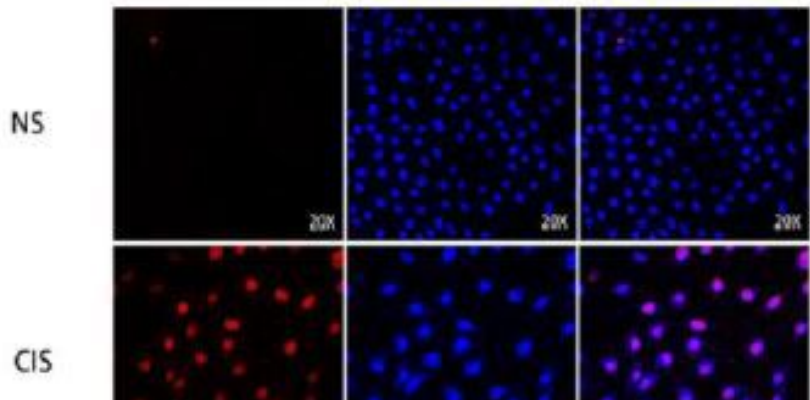

Cl

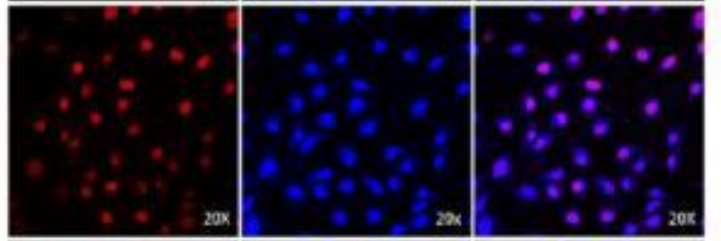

LiCL

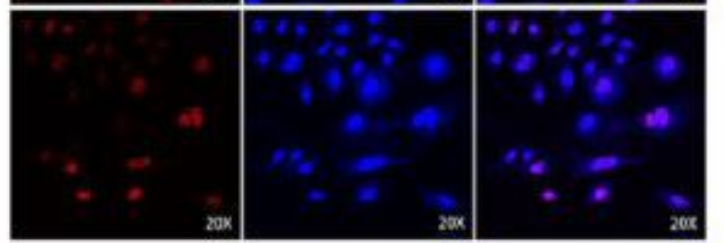

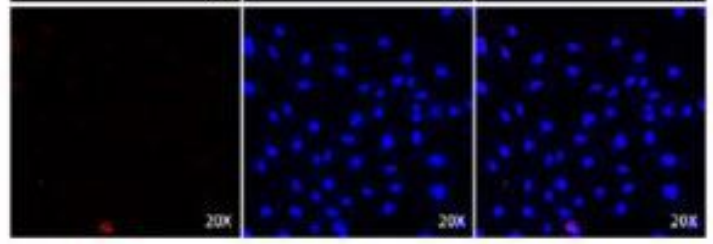

\section{Figure 4}

Licl can attenuate cisplatin-induced apoptosis. (A) CCK-8: HEI-OC1 cells were treated with 0, 10, 15, 20 , and $40 \mathrm{mmol} / \mathrm{L}$ Licl for $24 \mathrm{~h}$, respectively. The cell activity increased at $10 \mathrm{mmol} / \mathrm{L}$ and then decreased with the increase of concentration ( $N=6, P<0.05$ vs. NS). (B) HEI-OC1 cells were treated with air culture, air culture, $10 \mathrm{mmol} / \mathrm{L} \mathrm{Licl}$ for $24 \mathrm{~h}$, and then with air culture, $20 \mu \mathrm{mol} / \mathrm{L}$ cisplatin, $20 \mu \mathrm{mol} / \mathrm{L}$ cisplatin, 10 $\mathrm{mmol} / \mathrm{L} \mathrm{Licl} \mathrm{for} 24 \mathrm{~h}$. It can be seen from CCK-8 that Licl group suffered a lower loss of cell activity in cisplatin's toxicity compared to the cisplatin group. (C) Tunnel staining: Tunnel staining showed that HElOC1 cells were treated with air culture, air culture, $10 \mathrm{mmol} / \mathrm{L} \mathrm{Licl}$ for $24 \mathrm{~h}$, and then treated with air culture, $20 \mu \mathrm{mol} / \mathrm{L}$ cisplatin, $20 \mu \mathrm{mol} / \mathrm{L}$ cisplatin, and $10 \mathrm{mmol} / \mathrm{L}$ Licl for $24 \mathrm{~h}$, respectively, so as to determine the degree of apoptosis through Tunnel staining. It can be seen that the apoptosis of HEI-OC1 cells treated with $10 \mathrm{mmol} / \mathrm{L} \mathrm{Licl}$ was significantly reduced in the cisplatin toxicity. 
A

B

CS1 CS2 CL1CL2

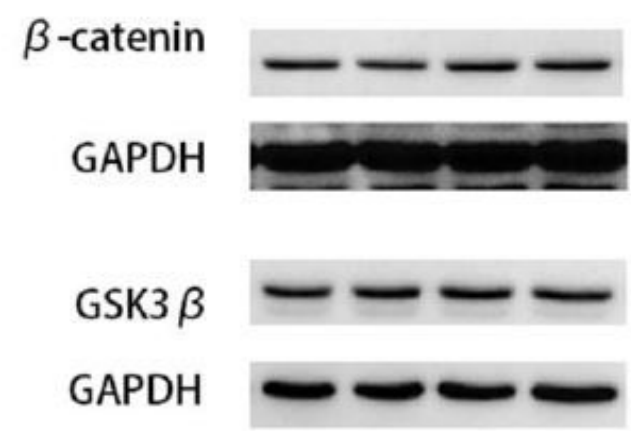

BMI1

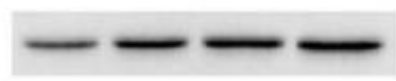

GAPDH

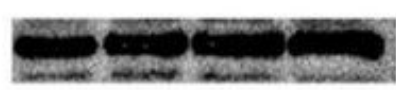

P53

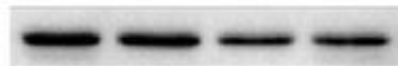

GAPDH

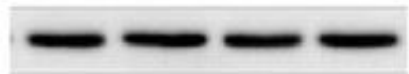

$\beta$-catenin

(nuclear)

PCNA
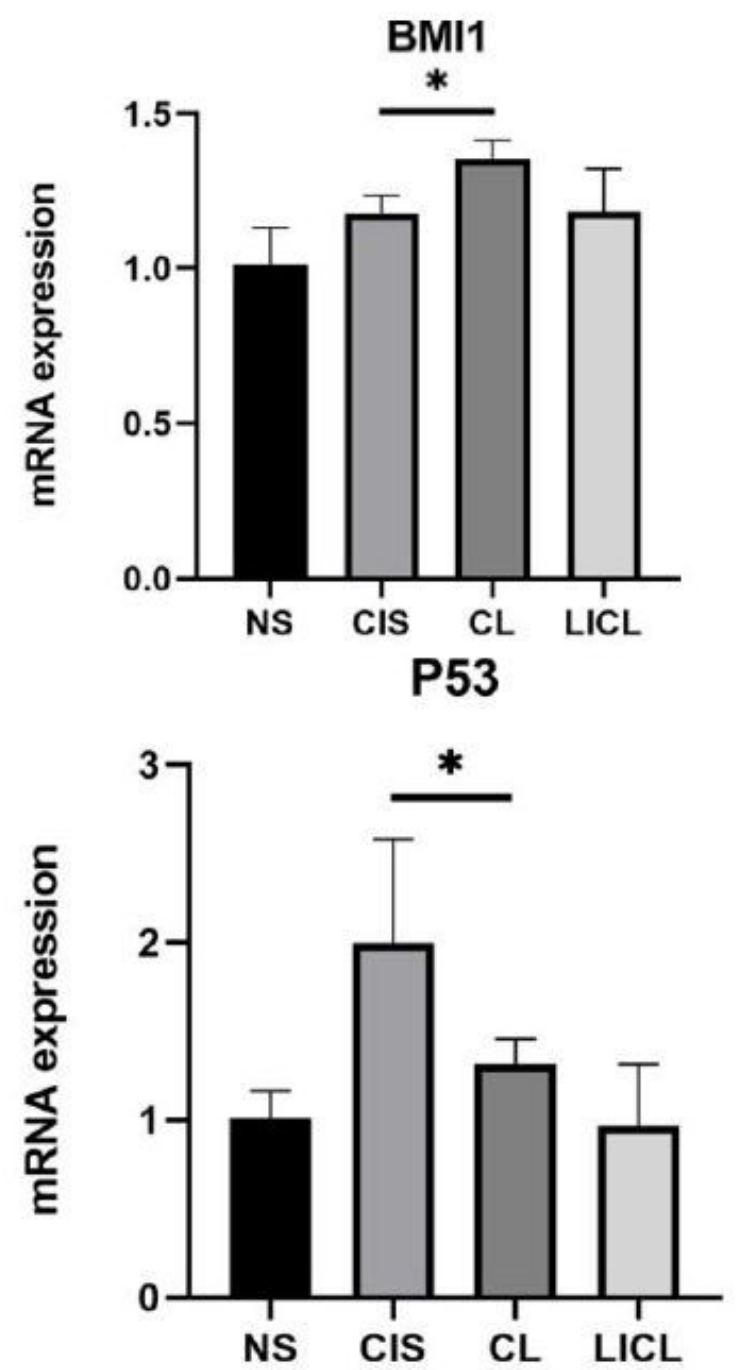

Figure 5

Activation of Wnt/ $\beta$-catenin signaling by Licl can increase the expression of BMI1 and inhibit the ARFMDM2-p53 signaling. (A) Western Blot: the changes in the expression levels of various proteins in cells after $\mathrm{HEl}-\mathrm{OC} 1$ were respectively treated with air culture and 10mmol/L Licl for $24 \mathrm{~h}$ and then $20 \mu \mathrm{mol} / \mathrm{L}$ cisplatin for $24 \mathrm{~h}$. (B) QPCR: expression of the BMI1 mRNA after HEI-OC1 was treated with empty culture and $10 \mathrm{mmol} / \mathrm{L} \mathrm{Licl}$ for $24 \mathrm{~h}$ and then $20 \mu \mathrm{mol} / \mathrm{L}$ cisplatin for $24 \mathrm{~h}$, respectively. $(\mathrm{N}=3, P=0.0193<0.5)$. (C) qPCR: expression of BMI1 mRNA after HEl-OC1 was treated with empty culture and 10mmol/L Licl for 24 $\mathrm{h}$ and $20 \mu \mathrm{mol} / \mathrm{L}$ cisplatin for $24 \mathrm{~h}$, respectively. $(\mathrm{N}=3, \mathrm{P}=0.0388<0.5)$. 